evidence which would command academic approval, and as far as is known no government agency has been asked by the police to assess the spectrographs. On the telephone, the manufacturer declined to say which police forces had bought the spectrographs.

Phoneticians both in Britain and the United States are considerably alarmed by the attempts to introduce voiceprints as legal evidence. It is well known that the voice changes with age and with emotion, and can be disguised and mimicked. Each such source of variability produces corresponding changes in spectrograms and voiceprint changes which are more than likely to conceal the posited but still unproved uniqueness of the individual voice. The circumstances in which recordings for legal use are likely to be made, for example by telephone tapping, are notorious for distorting sound; comparison of a voiceprint made from such a recording with one taken directly from the suspect presents yet further difficulties of interpretation.

Mr Kersta's Nature article of 1962 remains, as far as is known, the most serious attempt to evaluate voiceprints. Since then he has apparently been less cautious in his claims. Perhaps because of the lack of published material, there seems to have been a disinclination in academic circles to take these claims seriously. A thorough assessment is likely to be a lengthy and somewhat unrewarding task, which may be one reason why the several experiments which militate against the claims have been conducted on an informal basis and remain unpublished.

\section{How Much Electricity?}

THE electricity generating industry in Britain has just made an odd decision-that $£ 16$ million can be saved from the investment programmes because of revisions in the trend of demand for electricity. This reduction is very small when seen against the total investment programme of the electricity generating boards, and in the ordinary course of events would hardly be worthy of comment. But the $£ 16$ million cut has come on top of cuts of $£ 17$ million made in the public expenditure crisis of December 1967, and at a time when the Central Electricity Generating Board is talking cheerfully of a return to traditional growth rates for electricity consumption, after several years of relative stagnation. Those suspicious of the Ministry of Power's estimates have thus been given further ground for doubt; it looks as if the ministry's estimates are simply adjusted to fit short term capital shortages.

The industry's record in estimating demand over the past ten years has been woeful. First, in the early fifties, the estimates were pitched far too low, a mistake which led directly to the power cuts of 1962-63. The estimate made in 1953 for demand in 1959-60 was no less than 10 per cent too low. From this, the industry went to the other extreme, urged on by the "expansionist" phase in economic management between 1964 and 1966-the time of the National Plan. The estimates made in the early $60 \mathrm{~s}$ were as bad as those of the $50 \mathrm{~s}$, though in the other direction; the only thing that saved the CEGB from a vast over-capacity was its inability to get power stations finished on time. Thus in 1968-69, the plant actually in commission $(46,400$ MW) would have fallen 7 per cent short of demand if the original estimates had been right. In fact, it represents an over-capacity of about 25 per cent. The past two years, since the abandonment of the plan, have seen reductions in the estimates. Last year, for example, the Electricity Council said that demand in 1972-73 would be $54,000 \mathrm{MW}$; this year it says that this demand will not be reached until 1973-74, and that demand in $1972-73$ will be only $50,600 \mathrm{MW}$. The average rate of growth of consumption between now and then will be $7 \cdot 2$ per cent a year; last year the council thought it would be $7 \cdot 3$ per cent.

There seems to be no particular reason for believing that this latest estimate will be any more reliable than its predecessors. But it does seem to reflect a lack of optimism in the effects of devaluation which might not be endorsed by the Government. In any case, it is a pity to postpone investments now which in the long term are the only way of reducing electricity charges to the consumer. If the industry has too many power stations in 1974 , it can at least scrap some of the old and inefficient ones; but if it has too few, it will look very silly indeed.

Meanwhile, the Electricity Council is looking for a new chairman. Sir Ronald Edwards, chairman of the council since 1962, announced last week that he would resign at the end of October, to become chairman and chief executive of the Beecham Group. The job at present pays $£ 12,500$ a year, but may have to be increased to attract the right applicant. It is also possible that any new appointment would be tied in with a plan to reorganize the electricity generating industry.

\section{New Ways to Make Steel}

THe British Iron and Steel Research Association seems to have managed the transition from private to public status without disruption. Since the British steel industry was nationalized on July 28, 1967, BISRA has had two roles to fill-as the inter-group laboratories of the British Steel Corporation and as a research association continuing to serve the companies still in private hands. So far, the change is not apparent, at least in the work which is discussed in the annual report of BISRA, most of which is along familiar lines.

During the year trials began on a new steelmaking process, designed to make steel from cold charges. This uses an atomized spray of oil burning in oxygen as the only source of heat for steelmaking. Most of the development work is being carried on at Dorman Long (Steel) Ltd, where an 80 tonne vessel has been commissioned. The lessons learned with a small half tonne vessel are being applied to the larger scale development, and the intention is to devise the best possible working conditions and then to compare the process with the electric arc process. The charge is a mixture of scrap and pig-iron, and the burners use oil and oxygen in different proportions to produce different final steel compositions. Two kinds of burner have been used; a Dorman Long burner in which the oil is atomized with steam, and a BISRA design in which the atomization is carried out by what are called "swirl inserts". So far BISRA is not saying how well the process works.

Another major development in steelmaking, the spray process, has now passed out of BISRA's hands and is the responsibility of a wholly owned subsidiary, 